\title{
Entrainment in the Denmark Strait overflow plume by meso-scale eddies
}

\author{
G. Voet and D. Quadfasel \\ Institut für Meereskunde, KlimaCampus, University of Hamburg, Hamburg, Germany \\ Received: 14 October 2009 - Published in Ocean Sci. Discuss.: 11 November 2009 \\ Revised: 16 February 2010 - Accepted: 21 Februay 2010 - Published: 1 March 2010
}

\begin{abstract}
The entrainment of buoyant ambient water into the overflow plume of Denmark Strait and the associated downstream warming of the plume are estimated using time series of currents and temperature from moored instrumentation and classical hydrographic data. Warming rates are highest $(0.4-0.5 \mathrm{~K} / 100 \mathrm{~km})$ within the first $200 \mathrm{~km}$ of the sill, and decrease to $0.05-0.1 \mathrm{~K} / 100 \mathrm{~km}$ further downstream. Stirring by mesoscale eddies causes lateral heat fluxes that explain the $0.1 \mathrm{~K} / 100 \mathrm{~km}$ warming, but in the first $200 \mathrm{~km}$ from the sill also vertical diapycnal fluxes, probably caused by breaking internal waves, must contribute to the entrainment.
\end{abstract}

\section{Introduction}

The Meridional Overturning Circulation in the North Atlantic Ocean is the system of southward flow of cold and dense water at depth and the compensating northward flow of warm and buoyant water at the surface. This circulation is maintained by meridional density gradients in the deep ocean. The transformation of the buoyant surface component to the dense deep component takes place in the Labrador Sea (Schott et al., 2004) and the Nordic Seas (Mauritzen, 1996) where convective processes lead to the production of dense waters that contribute to the North Atlantic Deep Water, the principal component of the lower limb of the Meridional Overturning Circulation. The total amount of North Atlantic Deep Water leaving the subpolar North Atlantic southward is around $18 \mathrm{~Sv}\left(1 \mathrm{~Sv}=10^{6} \mathrm{~m}^{3} / \mathrm{s}\right)$ (Stahr and Sanford, 1999).

The deep water formed in the Labrador Sea enters the abyssal North Atlantic without topographic constraints. It contributes 4-6 Sv (Schott et al., 2004) to the North Atlantic Deep Water corresponding to around one third of its total

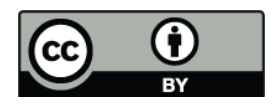

Correspondence to: G. Voet (gunnar.voet@zmaw.de) transport. About another $6 \mathrm{~Sv}$ are supplied as source waters from the Nordic Seas. These water masses pass the Greenland-Scotland Ridge and enter the abyssal North Atlantic mainly in the two overflows through the Faroe Bank Channel and Denmark Strait. After crossing the sills of the two straits, the dense overflow plumes are subject to strong entrainment of ambient water (Dickson and Brown, 1994). The plume transport is almost doubled by entrainment. Thus, entrainment processes are involved in the formation of North Atlantic Deep Water and contribute about another third or $6 \mathrm{~Sv}$ to it (Hansen et al., 2004).

Entrainment in the Denmark Strait overflow plume was apparent early from hydrographic sections, showing that the mean density contrast between plume and ambient water decreased with increasing distance from the sill (Smith, 1976). However, the amount of entrained water could not be quantified until direct current measurements at the sill and different sites downstream became available. First measurements with current meters showed an overflow volume transport of around $3 \mathrm{~Sv}$ at the Denmark Strait sill (Worthington, 1969). More recent measurements with moored Acoustic Doppler Current Profilers yield approximately the same transport (Macrander et al., 2005). Current meter measurements downstream of the sill show a transport increase to $5.2 \mathrm{~Sv}$ within $300 \mathrm{~km}$ distance from the sill (Dickson and Brown, 1994). Different entrainment regimes regarding the strength of entrainment were found along the path of the overflow plume. From velocity and hydrography surveys, entrainment rates were estimated that increased by about one order of magnitude from the sill to $125 \mathrm{~km}$ downstream from the sill where the overflow plume enters steeper topography (Girton and Sanford, 2003).

What are the processes that drive the strong entrainment? Both, turbulent mixing and lateral stirring, can lead to the mixing of ambient water into the overflow plume. Mixing through Kelvin-Helmholtz instabilities is induced by strong vertical velocity shear, horizontal velocity shear may lead to

Published by Copernicus Publications on behalf of the European Geosciences Union. 
mixing through horizontal instabilities. Meso-scale eddies can induce stirring of different water masses, the strong velocities of the overflow plume may induce Ekman pumping through bottom friction. These processes all have different length scales ranging from below one meter to several kilometers. With the data available at present, only the large scale processes can be resolved from measurements. For a budget of the different entrainment processes, we can calculate the large scale eddy stirring and estimate the Ekman pumping. The effect of small-scale processes like breaking internal waves can then be estimated as the residuum in the budget.

Current measurements and temperature records of the Denmark Strait overflow plume show a high variability on timescales of 2-5 days close to the sill (Ross, 1984) and 1-12 days about $500 \mathrm{~km}$ downstream (Dickson and Brown, 1994). Pulses of strong current velocity are accompanied by an increase in overflow plume height. These domes of cold water are in rotation and connected to surface eddies observed in satellite infrared imagery (Bruce, 1995; Krauss, 1996) and satellite altimetry (Høyer and Quadfasel, 2001). The meso-scale eddies reach throughout the whole water column. They have a diameter of $20-40 \mathrm{~km}$ and travel with the velocity of the overflow plume. Similar eddies have been observed with moorings in the overflow plume downstream of the Faroe Bank Channel overflow (Geyer et al., 2006). The breakup of an overflow plume into barotropic eddies was also simulated in laboratory experiments with dense currents on a sloping bottom in rotating tanks (Whitehead et al., 1990; Cenedese et al., 2003). Generation mechanisms for the observed eddies were investigated in numerical studies. A steady streamtube model resembling the overflow showed baroclinic instabilities at a period of 2.1 days and a wavelength of $80 \mathrm{~km}$, comparing well with dominant periods in mooring records (Smith, 1976). The partly barotropic outflow through Denmark Strait and the subsequent descent of the dense bottom current makes vortex stretching another possible eddy generation mechanism (Spall and Price, 1998). More complex 3-D models with realistic bottom topography explain the eddy formation with a combination of both baroclinic instability and vortex stretching (Jiang and Garwood, 1996; Krauss and Käse, 1998; Jungclaus et al., 2001).

As it almost doubles the overflow plume transport, entrainment strongly influences the formation rate of North Atlantic Deep Water. Furthermore, it modifies the final characteristics of the North Atlantic Deep Water as less dense ambient water is mixed into the overflow plume. We therefore regard entrainment as an important element of the Meridional Overturning Circulation. While the amount of entrained water into the Denmark Strait overflow plume is relatively well known, the relative contributions of horizontal and vertical turbulent processes to the entrainment are not quantified yet. This study is dedicated to the question of the importance of the horizontal turbulence associated with meso-scale eddies for the entrainment into the Denmark Strait overflow plume.
After giving an overview of the observational data used in this study in Sect. 2, we provide a theoretical basis for the calculation of eddy driven entrainment with a statistical approach in Sect. 3. We present overflow plume characteristics from time averaged quantitites and establish a mean plume warming rate along the plume pathway in Sect. 4. A warming rate from eddy driven heat fluxes is calculated in Sect. 5 . Conclusions are drawn in Sect. 6.

\section{Data}

Mooring arrays were set across the pathway of the Denmark Strait overflow plume at four different locations over the past twenty years (Fig. 1). The array located at the Denmark Strait sill consists of bottom mounted ADCPs with the first deployment in 1999 and sustained redeployments thereafter until present (Macrander et al., 2005; Quadfasel and Käse, 2007). Arrays A and B at 200 and $360 \mathrm{~km}$ distance from the sill were deployed in 1990 for periods of three months and one year, respectively (Dickson and Brown, 1994). Mooring array C at $520 \mathrm{~km}$ distance downstream of the sill was deployed repeatedly from 1986 to 1990 (Dickson and Brown, 1994) and again from 1995 until present (Dickson et al., 2008) in one year periods. In this study we use array $\mathrm{C}$ data from the deployment period 2001/2002 as this provides the best spatial coverage of the overflow plume together with minimum instrument failure. All moorings at arrays A, B and C were equipped with two to four Aanderaa Rotor Current Meters measuring speed and direction of the current. In addition temperature sensors were attached to all instruments.

The coordinate system for each mooring is rotated to be aligned with the mean flow, thus each mooring is allocated its own coordinate system. The angle of rotation is given by the mean direction measured at the instrument just above the bottom Ekman layer. In these new coordinate systems, the $\mathrm{v}$-component of the current points toward the mean flow direction (SW-W) while the u-component points perpendicular to the right (upslope), as in a regular right-handed coordinate system. Figure 2 shows an illustration of the rotated coordinate system together with an example for the time series recorded by an instrument at the central mooring at array $\mathrm{C}$.

Hydrographic data from the overflow region is used in addition to the mooring data (Fig. 1). Six standard sections normal to the slope, of which four coincide with the location of the mooring arrays, were served annually since 1997 (Dickson et al., 2007). The hydrographic data complements the high temporal resolution mooring time series with snapshots of high spatial resolution.

\section{Heat fluxes and entrainment}

The entrainment of buoyant ambient water into the dense overflow plume decreases the overall density of the plume while it increases the transported volume. The mooring time 


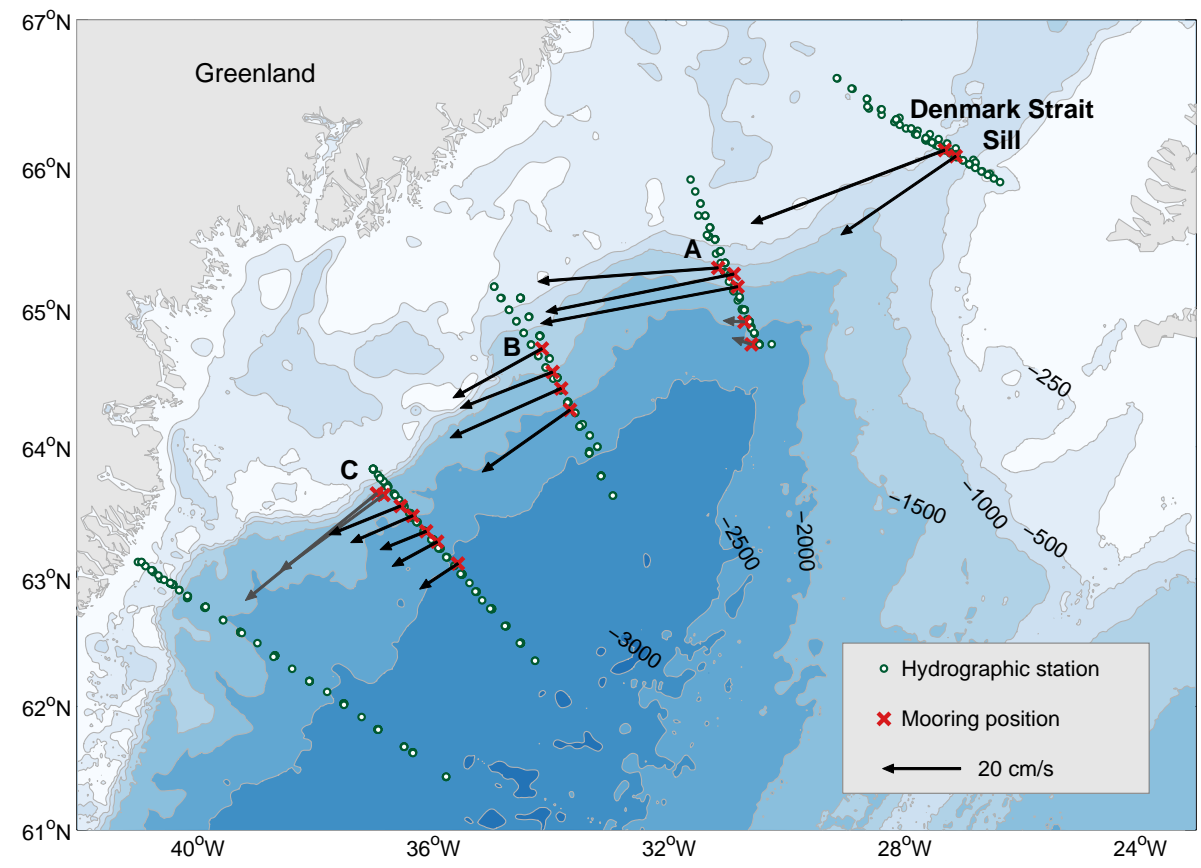

Fig. 1. Map showing the bathymetry of the Denmark Strait and the area south of it. Green circles mark the positions of hydrographic stations. One hydrographic section further south off Cape Farewell is not shown on the map. Red crosses mark the mooring positions. Mean velocities from the instruments (array A to C) or bins (sill array) just above the bottom Ekman layer are shown with the black vectors. Mean velocities from instruments that were not situated in the overflow plume are shown with grey vectors.

series only partially include density data. Instead of density fluxes we use the heat flux into the overflow plume as a proxy for the entrainment rate. This is justified with salinity values varying by only about 0.05 between the overflow plume and the ambient water (see e.g. the salinity section in Rudels et al., 1999), making density dependent on temperature only in a first approximation.

With heat defined as the product of density times specific heat times temperature, $Q=\rho c_{p} T$, heat fluxes per unit area in a turbulent flow are given by the heat transport equation:

$$
\begin{aligned}
\underbrace{\frac{\partial \bar{Q}}{\partial t}}_{\text {ocal change }}+\underbrace{\bar{u} \frac{\partial \bar{Q}}{\partial x}+\bar{v} \frac{\partial \bar{Q}}{\partial y}+\bar{w} \frac{\partial \bar{Q}}{\partial z}}_{\text {Advective terms }} \\
=\underbrace{\frac{\partial \overline{\partial x} \overline{u^{\prime} Q^{\prime}}+\frac{\partial}{\partial y} \overline{v^{\prime} Q^{\prime}}+\frac{\partial}{\partial z} \overline{w^{\prime} Q^{\prime}}}{\partial x^{\prime}}}_{\text {Turbulent terms }}
\end{aligned}
$$

Here, $\bar{Q}$ and $(\bar{u}, \bar{v}, \bar{w})$ are the mean heat and the mean velocity components of the flow while $Q^{\prime}$ and $\left(u^{\prime}, v^{\prime}, w^{\prime}\right)$ are the fluctuations of these. Integrating this equation over a closed volume gives the change of heat within that volume.

The mooring data only provides measurements of temperature and velocity at certain points. The integration over closed plume surfaces will be done later and in the following discussion we will simply use the temperature transport equation per unit area:

$$
\begin{aligned}
\underbrace{\frac{\partial \bar{T}}{\partial t}}_{\text {Local change }}+\underbrace{\bar{u} \frac{\partial \bar{T}}{\partial x}+\bar{v} \frac{\partial \bar{T}}{\partial y}+\bar{w} \frac{\partial \bar{T}}{\partial z}}_{\text {Advective terms }} \\
=\underbrace{\frac{\partial}{\partial x} \overline{u^{\prime} T^{\prime}}+\frac{\partial}{\partial y} \overline{v^{\prime} T^{\prime}}+\frac{\partial}{\partial z} \overline{w^{\prime} T^{\prime}}}_{\text {Turbulent terms }}
\end{aligned}
$$

Geometry and dynamics of the overflow plume allow a simplification of the temperature transport equation. We consider the overflow to be stationary in zeroth approximation. This eliminates the time derivative of the mean temperature. Since the coordinate system is aligned with the mean flow direction, the mean velocity normal to the mean flow, $\bar{u}$, is zero by definition. We compare the order of magnitude of the remaining two advective terms against each other as follows. A vertical mean velocity $\bar{w}$ may arise from a divergent Ekman transport at the bottom. The magnitude of $\bar{w}$ can be estimated from the mean downstream velocity $\bar{v}$ as it determines the Ekman transport $T_{\mathrm{E}}$,

$T_{\mathrm{E}}=\frac{c_{\mathrm{D}} \bar{v}^{2}}{f}$,

with the bottom drag coefficient $c_{\mathrm{D}}=10^{-3}$ (Käse et al., 2003) and the Coriolis parameter $f$. Division of $T_{\mathrm{E}}$ by the 


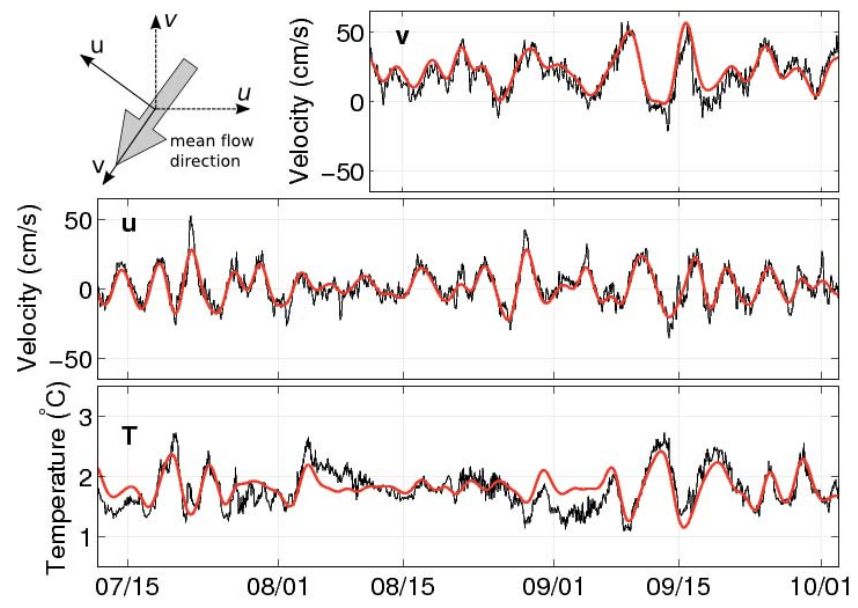

Fig. 2. Time series of temperature (lower panel), velocity perpendicular to the mean flow (middle panel) and along the mean flow direction of the overflow plume (upper panel). The time series were recorded at the central mooring at array $\mathrm{C}$ at a height of $102 \mathrm{~m}$ above the bottom. Shown here is only a part of the complete time series that has a length of one year. Black curves give the full spectrum of the data at a resolution of one hour. Red curves show bandpass filtered time series with an added mean value to make them comparable to the original data. The inset to the upper left illustrates the rotation of the original coordinate system with east and north components (dashed arrows) to a coordinate system aligned with the mean flow (full arrows) as used for $\mathrm{u}$ and $\mathrm{v}$ shown here.

Ekman layer depth $d_{\mathrm{E}}$ yields an estimate of the mean Ekman velocity $\overline{u_{\mathrm{E}}}$. The Ekman velocity has its maximum at the plume core where the highest mean velocities $\bar{v}$ are reached. It decreases to the sides of the overflow plume. By making the assumption of zero Ekman velocities outside the plume $u_{\mathrm{E}}($ edge $)=0$, the divergence can be estimated:

$\frac{\partial u_{\mathrm{E}}}{\partial x}=\frac{u_{\mathrm{E}}(\text { core })-u_{\mathrm{E}}(\text { edge })}{x(\text { core })-x(\text { edge })}$

This divergence must be balanced by a vertical velocity $\bar{w}$. It can be calculated from the equation of continuity:

$\frac{\partial w}{\partial z}+\frac{\partial u}{\partial x}=0 \Rightarrow w=\frac{\Delta u}{\Delta x} \Delta z$

A mean downstream velocity $\bar{v}=0.2 \mathrm{~m} / \mathrm{s}$ leads to a mean Ekman velocity of $\overline{u_{\mathrm{E}}}=0.02 \mathrm{~m} / \mathrm{s}$. The resulting vertical velocity is $\bar{w}=4 \times 10^{-5} \mathrm{~m} / \mathrm{s}$. The temperature gradients $d T / d z$ and $d T / d y$ can be estimated from temperature measurements in the overflow plume and the ambient water. These show a temperature difference of about $5 \mathrm{~K}$ over a distance of $1000 \mathrm{~m}$ that lead to a gradient of $d T / d z=5 \times 10^{-3} \mathrm{~K} / \mathrm{m}$. The mean plume temperature in the $y$-direction changes by about $1.5 \mathrm{~K}$ over a distance of $500 \mathrm{~km}$ as will be shown in the next section. This leads to a temperature gradient of $d T / d y=3 \times 10^{-6} \mathrm{~K} / \mathrm{m}$. With these values, the magnitude of the two remaining advective terms in the temperature transport equation is

$\bar{w} \frac{\partial T}{\partial z} \cong 2 \times 10^{-7} \quad \bar{v} \frac{\partial T}{\partial y} \cong 1 \times 10^{-6}$.

Hence, the horizontal advective term is approximately one order of magnitude larger than the vertical advective term ${ }^{1}$. This indicates that the vertical advective temperature flux may be small enough to be neglected in the analysis. Variations of the drag coefficient and local fluctuations of mean velocity and vertical temperature gradient can, however, lead to considerable variations in the size of the advective terms.

The two horizontal turbulent terms can be compared to each other. The divergence of turbulent motion in the $x$ direction is very strong. There is a transition from (nearly) zero turbulent motion outside the plume to vigorous turbulent motion in the plume centre over a distance of less than $50 \mathrm{~km}$. The eddies travel with the overflow plume in the $y$ direction, leading to only little changes in turbulent motion along the $y$-direction. We thus also neglect the term with $v^{\prime}$.

The remaining terms show that the warming of the plume along its path is driven by turbulent temperature exchanges in the $x$ - and $z$-direction and a possible contribution of neglected terms included here as $\epsilon$ :

$\bar{v} \frac{\partial \bar{T}}{\partial y}=\frac{\partial}{\partial x} \overline{u^{\prime} T^{\prime}}+\frac{\partial}{\partial z} \overline{w^{\prime} T^{\prime}}+\epsilon$.

With our data we can calculate the warming rate along $y$ and horizontal turbulent temperature fluxes along $x$.

\section{Structure of the overflow plume and its downstream warming}

After crossing the Denmark Strait sill, the overflow plume accelerates on the first $125 \mathrm{~km}$ until it reaches its maximum mean velocity of about $65 \mathrm{~cm} / \mathrm{s}$ (Girton and Sanford, 2003). Thereafter the mean velocity decreases to about $45 \mathrm{~cm} / \mathrm{s}$ at mooring array A, $25 \mathrm{~cm} / \mathrm{s}$ at array B and $20 \mathrm{~cm} / \mathrm{s}$ at array C (Fig. 1). At all three arrays the flow has a baroclinic structure with highest velocities close to the bottom.

The eddy kinetic energy $K_{\mathrm{E}}$ of the flow is defined as

$K_{\mathrm{E}}=\frac{1}{2}\left(\overline{u^{\prime 2}}+\overline{v^{\prime 2}}\right)$

where $u^{\prime}$ and $v^{\prime}$ denote the fluctuations of the mean flow. As we are interested in the energy of the meso-scale eddies, we exclude not only the mean of the time series but also variability deriving from processes other than eddies, e.g. internal waves or tides. The tidal signal is estimated by means of

\footnotetext{
${ }^{1}$ The estimate for $\bar{w}$ calculated here gives an upper limit. An opposite Ekman transport at the upper boundary of the plume and non-zero Ekman transports at the plume edges lead to a reduction of the estimate.
} 
harmonical analysis (software provided by Pawlowicz et al., 2002) and substracted from the time series. This removes only about $5 \%$ of the overall velocity variance as the tides are weak in this area.

Using a bandpass filter we remove the remaining variability on long and short timescales while the signal in the frequency domain of the meso-scale eddies is kept. Figure 3 shows spectra of velocity time series recorded by the moorings. The time scale of the eddies grows with increasing distance from the sill and we therefore use different filter parameters for each mooring array to account for this increase: cut-off periods for the bandpass filter chosen are $28 \mathrm{~h}$ to $200 \mathrm{~h}$ at mooring array A, $36 \mathrm{~h}$ to $200 \mathrm{~h}$ at array B and $60 \mathrm{~h}$ to $300 \mathrm{~h}$ at array C. Thus, about 3-4 eddies are covered within the bandwidth.

We use the bandpass filtered time series $u^{\prime}$ and $v^{\prime}$ to calculate mean eddy kinetic energies. The highest eddy kinetic energies are found in the region of the plume core (Fig. 4), defined here as the part of the plume where the highest downstream velocities are reached. In contrast to the mean velocities that have their maximum close to the bottom, the mean eddy kinetic energy is highest at the top of the overflow plume at all mooring arrays. It decreases from around $200 \mathrm{~cm}^{2} / \mathrm{s}^{2}$ at arrays $\mathrm{A}$ and $\mathrm{B}$ to around $100 \mathrm{~cm}^{2} / \mathrm{s}^{2}$ at array $\mathrm{C}$.

The overflow plume is generally defined as water with a density anomaly higher than $27.8 \mathrm{~kg} / \mathrm{m}^{3}$ (Dickson and Brown, 1994) corresponding to temperatures below $2-3^{\circ} \mathrm{C}$. For a separation of the overflow water and the overlying water masses at each array we use the temperature time series available from all moorings. The temperatures vary on approximately the same time scale as the plume velocities, reflecting the variability in plume height. When domes of cold overflow water pass a mooring the height of the plume boundary can change by several hundred meters. This makes the temperature data from the moorings, despite their low spatial resolution, a better choice for the determination of the upper limiting isotherm than data from hydrographic surveys that only consist of single snapshots once a year.

From the temperature time series and the hydrographic data set we calculate mean plume temperatures at several sites downstream of the sill. These mean temperatures provide an estimate for the mean plume warming rate with respect to the distance from the sill. One way to find the temperature change along the plume pathway is to calculate the mean temperature over the whole cross-sectional area below the limiting upper isotherm. This can be done for each hydrographic section and for the mooring arrays A, B and C. The mooring array at the sill only has bottom temperature time series that do not allow this calculation. A second way to determine a mean plume temperature is to calculate the mean bottom temperatures of the plume at each mooring array. This can also be done with the mooring array at the sill. The core of the plume is here defined as the three time series with the lowest mean temperatures from each array. The

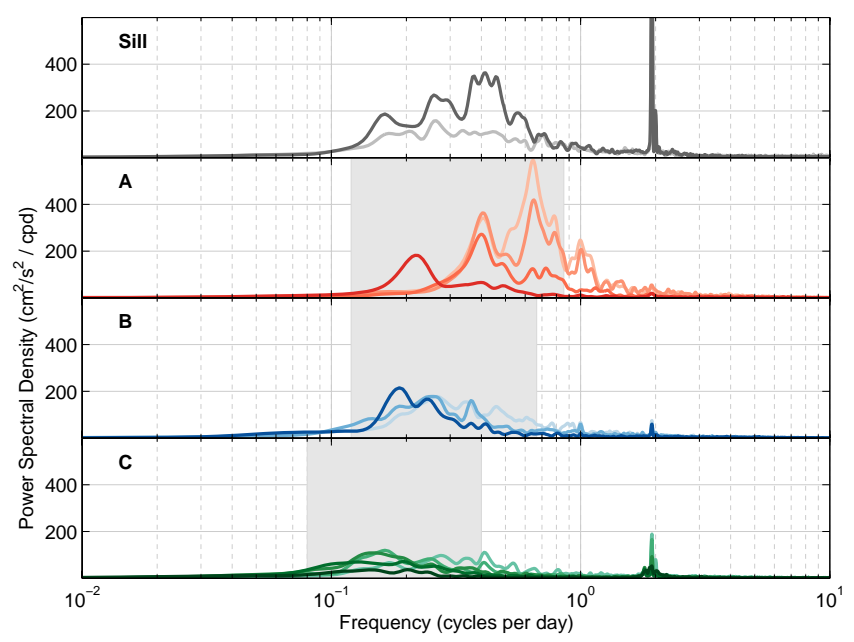

Fig. 3. Power spectral density calculated from velocity time series at each mooring and array. The velocity component perpendicular to the mean flow direction was used. Colours from light to dark correspond to mooring depth at the shelf from shallow to deep. The grey shaded areas for arrays A to $\mathrm{C}$ show the frequency domain that is used for the bandpass filtering.

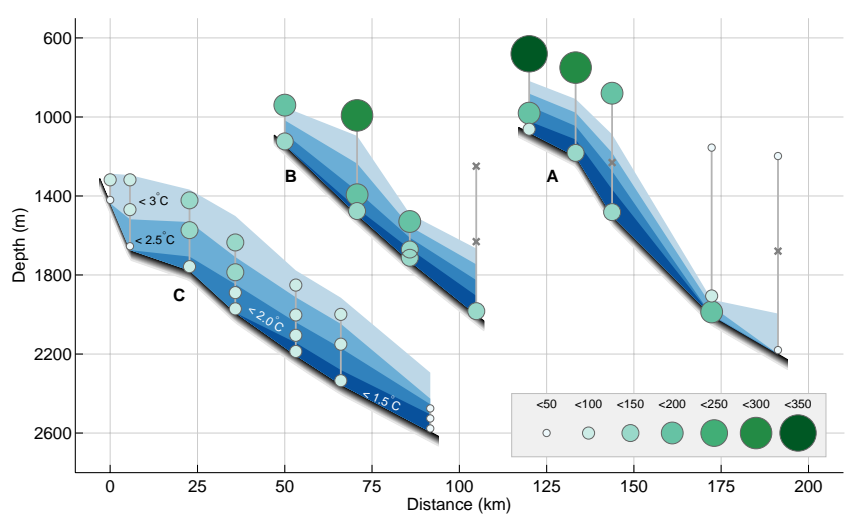

Fig. 4. Mean eddy kinetic energies $\left(\mathrm{cm}^{2} / \mathrm{s}^{2}\right)$ at mooring arrays A to C. The green circles show the size of the eddy kinetic energy at each current meter. The eddy kinetic energies were calculated from the bandpass filtered velocity time series. The blue shaded area shows the mean temperature structure of the overflow plume as calculated from the temperature time series at each instrument.

mean temperature for each mooring array is then calculated as the mean of these three values.

The mean plume temperatures calculated in both ways are shown in Fig. 5. Both the mean bottom temperatures and the vertically averaged temperatures increase by about $1 \mathrm{~K}$ on the first $200 \mathrm{~km}$. Farther away from the sill the warming is smaller with less than $0.1 \mathrm{~K}$ per $100 \mathrm{~km}$ for the vertical averaging method and about $0.1 \mathrm{~K}$ per $100 \mathrm{~km}$ for the bottom temperature method. 


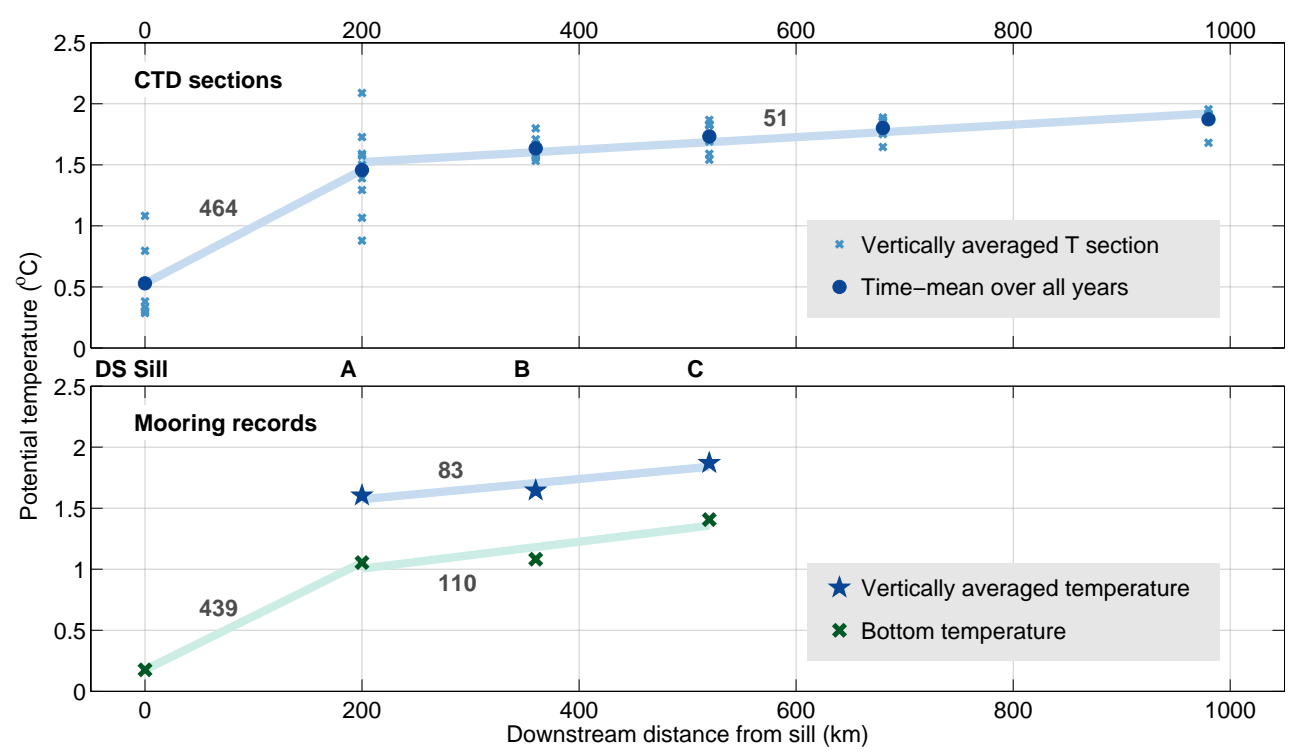

Fig. 5. Mean plume temperatures downstream of the Denmark Strait sill. The upper panel shows mean plume temperatures calculated from hydrographic sections occupied between 1997 and 2008. For each section and each year, the mean plume temperature for the cross-sectional area below the $2.5^{\circ}$ isotherm was calculated (blue crosses). Blue dots show the mean plume temperature at each section as a time mean over the individual years. As the measurements show two different warming regimes, temperature gradients were calculated with linear fits for the distance from the sill to the first section downstream and from thereon to a section about $1000 \mathrm{~km}$ downstream of the Denmark Strait sill. Lines show the linear fits to the mean plume temperatures, the numbers give the temperature gradients in $\mathrm{mK}$ per $100 \mathrm{~km}$. The lower panel shows mean plume temperatures as measured by the mooring instruments. The vertically averaged temperature was calculated as for the hydrographic sections. The bottom temperature was calculated by taking the mean over the three coldest bottom-near time series at each array. Temperature gradients are shown as in the upper panel.

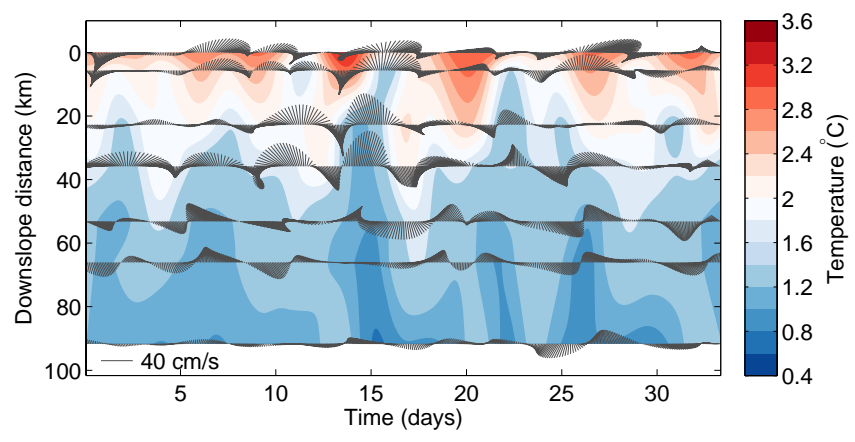

Fig. 6. Hovmoeller diagram of bottom temperatures (within $50 \mathrm{~m}$ of the bottom) at array $\mathrm{C}$ showing bandpass filtered data. Overlayn are stick plots of bandpass filtered velocity time series recorded at the same locations. A reference velocity for the stick plots is shown to the lower left.

\section{Eddy heat transports}

The overflow plume has high eddy kinetic energies on the time scale given by the meso-scale eddies. We now estimate the contribution of eddy stirring to the warming of the overflow plume, i.e. its contribution to the entrainment. An estimate for eddy driven heat transports into the overflow plume is first illustrated with data from mooring array $\mathrm{C}$. This dataset is more comprehensive than the two other arrays from which the results will be presented thereafter.

\subsection{Eddy heat transports at array C}

The rotational motion of the eddies does not lead to a net water mass transport since the time mean of the current fluctuation $\overline{u^{\prime}}$ is zero by definition. However, a net temperature flux $\overline{u^{\prime} T^{\prime}}$ can take place by the transport of warm and cold water in opposite directions. The variation of $\overline{u^{\prime} T^{\prime}}$ across the plume corresponds to the horizontal turbulent term in the temperature transport (Eq. 2). We focus again on the mesoscale eddies by using the bandpass filtered time series $u^{\prime}$ and $T^{\prime}$. Figure 6 illustrates the correlation between $u^{\prime}$ and $T^{\prime}$. The stick plot shows the rotational motion of the overflow plume and its relation with temperature fluctuations. The fluctuations of the current on the eddy time scale lead to a redistribution of warm and cold water.

Figure 7 shows the mean eddy temperature fluxes at array $\mathrm{C}$. The region of highest eddy temperature flux corresponds to the region of highest eddy kinetic energy. The direction of $\overline{u^{\prime} T^{\prime}}$ has a similar pattern for all moorings in the array. The eddy temperature flux is directed downslope at the 


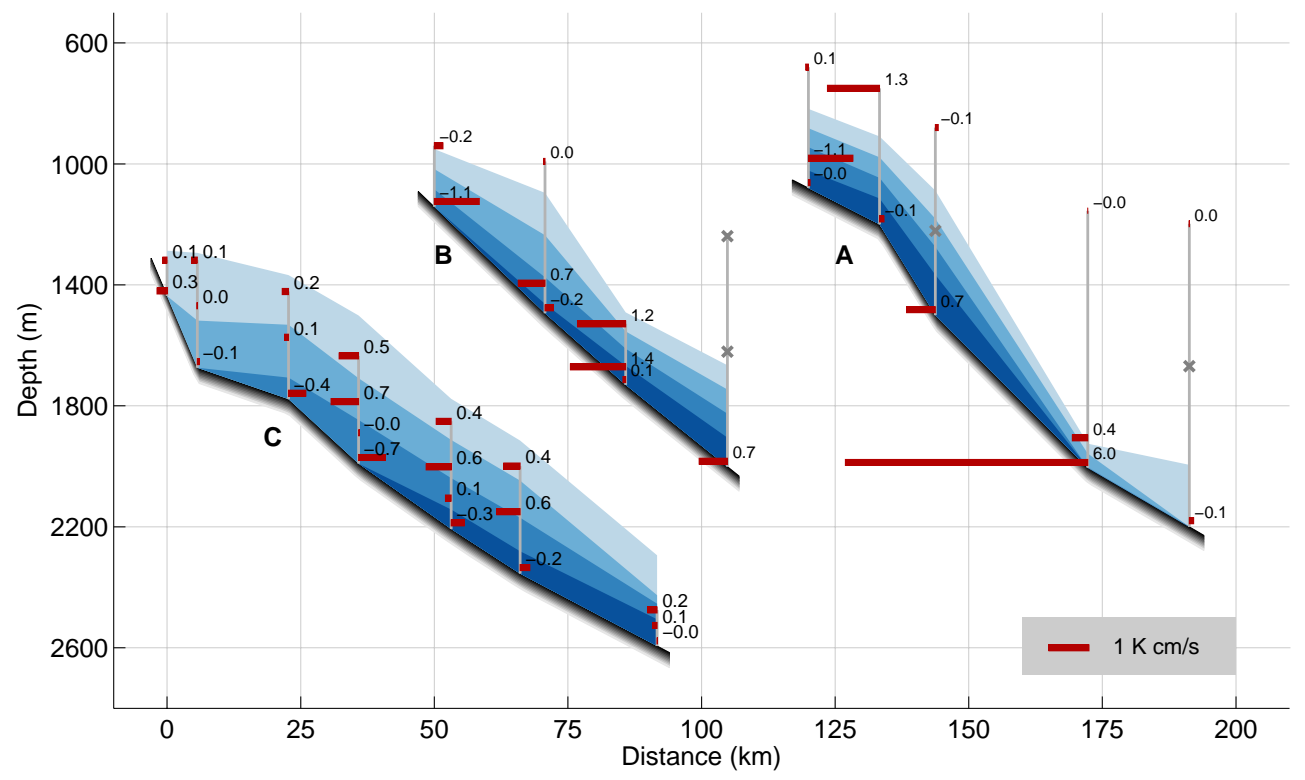

Fig. 7. Mean eddy temperature fluxes $\overline{u^{\prime} T^{\prime}}(\mathrm{K} \mathrm{cm} / \mathrm{s})$ at arrays $\mathrm{A}$ to $\mathrm{C}$. The red bars give the direction and magnitude of the mean eddy temperature flux. A scale for the red bars is given to the lower right. Numbers next to the red bars give the exact magnitude of the mean eddy temperature flux. Grey crosses mark instruments where no mean eddy temperature flux could be calculated. The temperature structure of the plume is shown as in Fig. 4.

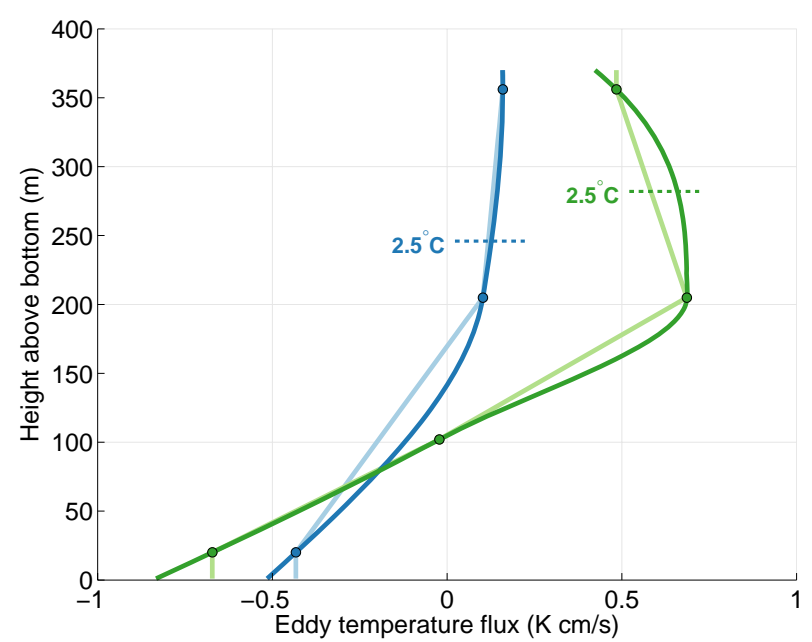

Fig. 8. Example for the interpolation of mean eddy temperature fluxes with height with data from two moorings at array C. Dots show mean eddy temperature fluxes as calulated at the height of the current meters. Lines in light color show the vertical interpolation of the mean eddy temperature flux with a linear method. Dark lines show vertical interpolation with polynomials. The dashed lines give the mean $2.5^{\circ} \mathrm{C}$ isotherm at the location of the mooring that serves as upper integration boundary for the results in Fig. 9. bottom and reverses with increasing height above seabed. In both cases, the temperature flux is opposite to the temperature gradient. Thus, not surprisingly, heat is transported from warm into cold regions. The magnitude of $\overline{u^{\prime} T^{\prime}}$ between 0.1 and $1 \mathrm{~K} \mathrm{~cm} / \mathrm{s}$ is up to an order of magnitude smaller than the products of the standard deviations of $u$ and $T$ that have a magnitude of about $4 \mathrm{~K} \mathrm{~cm} / \mathrm{s}$. The product of the standard deviations may be regarded as the maximum possible temperature transport due to fluctuations of velocity and temperature. Its difference to the mean eddy temperature flux calculated here is partly due to variability outside the bandwith of the bandpass filter. Furthermore, the correlation between velocity and temperature fluctuation does not always have the same phase. Figure 6 shows positive and negative correlation of current and temperature fluctuations.

Interpolation, subsequent vertical integration of the eddy temperature fluxes from the bottom to the limiting upper isotherm and multiplication by specific heat and density gives the net eddy heat transport at a mooring line. Usually there are two to four instruments at each mooring over a vertical distance of about $300 \mathrm{~m}$. Two different methods are used for the vertical interpolation between the instruments. In the first method, the profiles are interpolated linearly between the data points and taken constant elsewhere. In the second method, polynomials are used for data inter- and extrapolation. Figure 8 shows a examples for the two interpolation methods. 


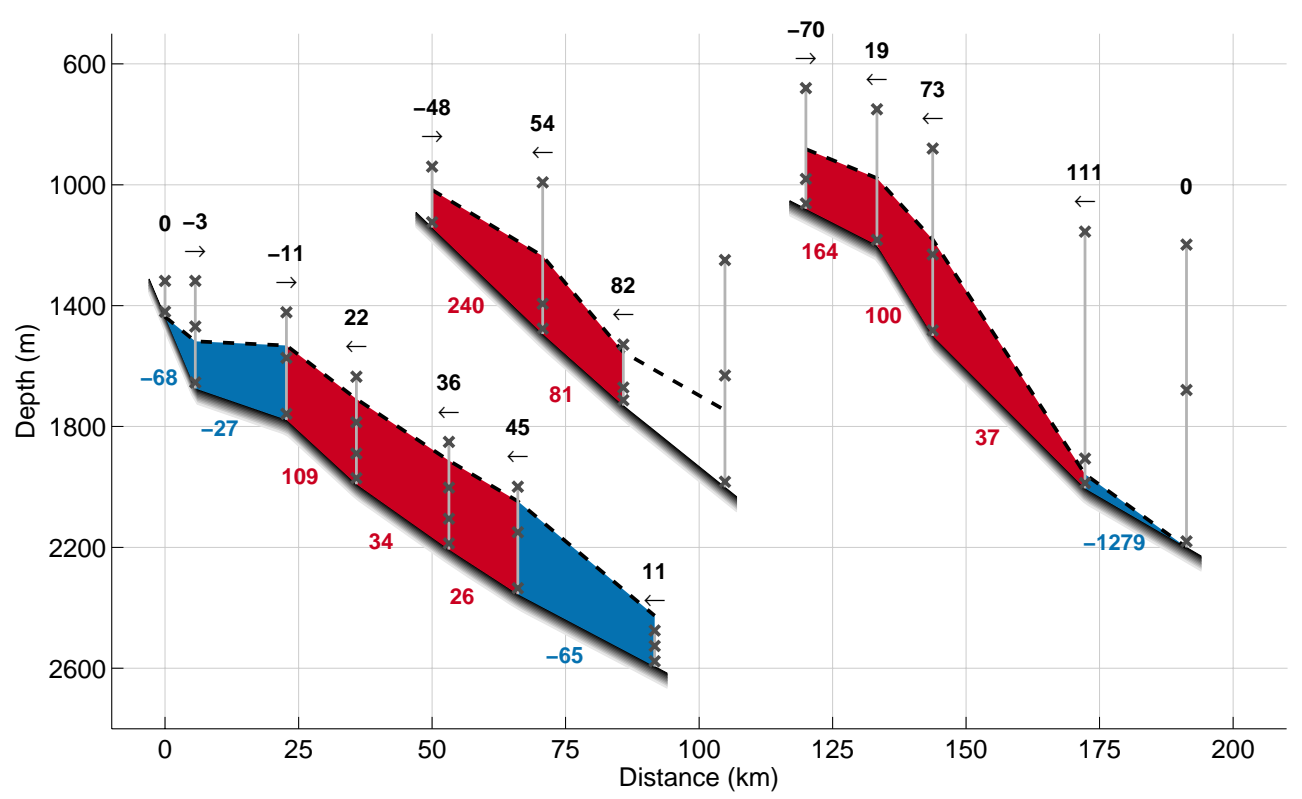

Fig. 9. Net eddy heat transports $\left(10^{5} \mathrm{~J} / \mathrm{ms}\right)$ at the mooring lines are shown with numbers and arrows above each mooring. The net eddy heat transport was calculated by interpolating and integrating the mean eddy temperature fluxes up to the limiting $2.5^{\circ} \mathrm{C}$ isotherm that is shown by the dashed black line. Red and blue colours show convergences and divergences of the net eddy heat transport in each box. Numbers below each box give the net warming rate $(\mathrm{mK} / 100 \mathrm{~km})$ for each box.

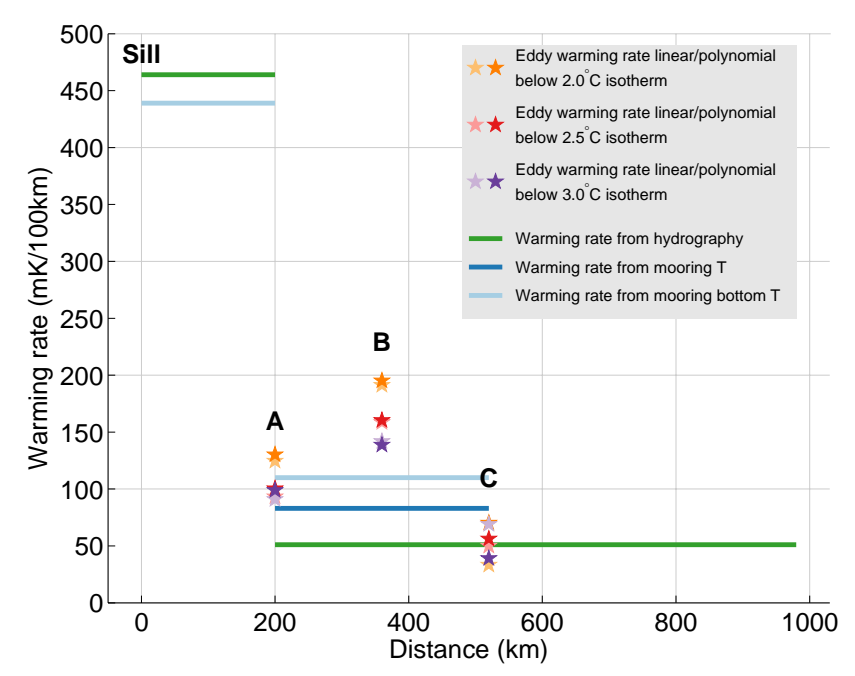

Fig. 10. Comparison of plume warming rates derived from direct temperature measurements as calculated in Fig. 5 (lines) and eddy driven warming rates of the plume core (stars). The different warming rates from direct temperature measurements stem from different calculation methods as explained in Sect. 4. Results from two different interpolation methods and three different upper limiting isotherms are shown for the eddy driven warming rates.
We use the $2.0^{\circ} \mathrm{C}, 2.5^{\circ} \mathrm{C}$ and $3.0^{\circ} \mathrm{C}$ isotherms as upper integration boundaries. Together with the two vertical interpolation methods for the eddy temperature fluxes this results in six different realizations for the following calculation of net eddy heat transports.

Each pair of moorings forms a box together with the limiting upper isotherm. The net eddy heat transport into these boxes is the sum of the eddy heat transports through both sides. Figure 9 shows the vertically integrated eddy heat fluxes and the net eddy heat transport into the boxes for the $2.5^{\circ} \mathrm{C}$ case. The eddy heat fluxes lead to a net warming in the centre of the plume. The region of the plume edges is cooled by the eddy heat transports. The position of the convergent region of eddy heat transport varies with the different plume boundary definitions. The region is situated downslope for the $2.0^{\circ} \mathrm{C}$-plume while it is more pronounced upslope for the $3.0^{\circ} \mathrm{C}$-plume.

By making the assumption that the eddy heat transport observed at the array $\mathrm{C}$ is regionally a steady process, we are able to calculate a warming rate per downstream distance. The time period for which the plume is exposed to the eddy mixing process is calculated from the mean plume velocity. We use a mean velocity of $20 \mathrm{~cm} / \mathrm{s}$ at array C. This is less than the mean bottom velocity of about $25 \mathrm{~cm} / \mathrm{s}$ as it gives a vertical averaged value of the whole plume. The highest warming rate for a single box is $100 \mathrm{mK}$ per $100 \mathrm{~km}$. The mean value for the convergent part of the plume, i.e. the part of the plume that gains heat through eddy heat transports, 
is $54 \mathrm{mK}$ per $100 \mathrm{~km}$. The warming rates derived from the two other boundary definitions are of the same order of size, with $72 \mathrm{mK}$ per $100 \mathrm{~km}$ for the $2.0^{\circ} \mathrm{C}$-plume area and $45 \mathrm{mK}$ per $100 \mathrm{~km}$ for the $3.0^{\circ} \mathrm{C}$-plume area. A comparison of the results from linear and polynomial interpolation gives an estimate for the uncertainty of the calculations. The warming rates for the whole convergent plume area differ by $11 \%$ with the 2.5 and $3.0^{\circ} \mathrm{C}$-boundary and by $43 \%$ with the $2.0^{\circ} \mathrm{C}$ boundary.

\subsection{Eddy heat transports at arrays A and B}

The eddy heat fluxes at the two upstream arrays A and B are calulated in the same way as for array C. Only the parameters for the bandpass filters are different, as described above.

The eddy temperature fluxes at the two arrays are shown in Fig. 7. The eddy temperature fluxes at the bottom converge in the centre of the plume at both arrays. This indicates that the whole plume core is covered by the mooring arrays. The magnitude of the eddy temperature fluxes is roughly the same at both arrays and approximately twice as high as at array C. Only the eddy temperature flux at the bottom instrument of mooring four at array A is five times larger than all other eddy temperature fluxes calculated here. This is the point where the isotherms indicate the location of the plume edge. It appears to be a region of strong mixing, possibly because of the strongly inclined isotherms. Diapycnal mixing induced by horizontal eddy motion may take place here.

Net eddy heat transports into the overflow plume, limited again by the $2.5^{\circ} \mathrm{C}$ isotherm, are shown in Fig. 9. The highest convergence in eddy heat transport is found at the upper part of the slope at both arrays. At the lower edge of the plume at array A strong cooling is observed. This results from the high eddy heat flux in combination with the small volume of the box. The data from array B was not sufficient for a calculation of the eddy heat transport at the lower part of the slope.

At both arrays the magnitude of the convergences in heat transports is approximately three times higher than at array $\mathrm{C}$. The highest value is found upslope at both arrays. However, lowering the upper plume boundary to $2.0^{\circ} \mathrm{C}$ does not shift the convergent region downslope as it was the case at array C. At array A, the region of convergent eddy heat transport for the $2.0^{\circ} \mathrm{C}$-plume is even shifted upslope as only the upper two boxes show a net warming. This indicates that the plume core has not migrated downhill yet.

To calculate plume warming rates from the eddy heat transports, the mean plume velocity is again used to estimate the time that the eddy mixing process can act on the plume. The mean plume velocity is $45 \mathrm{~cm} / \mathrm{s}$ at array A while at array B the plume has slowed down to $25 \mathrm{~cm} / \mathrm{s}$ (Fig. 1). These values are chosen to represent the mean velocity up to the plume boundary. Compared to array $\mathrm{C}$ the plume velocities are still high. They lead to shorter time periods that the eddy mixing is effective than farther downstream.
We find high eddy induced plume warming rates of up to $200 \mathrm{mK} / 100 \mathrm{~km}$ at the upper part of the slope at both arrays. The overall warming rates per $100 \mathrm{~km}$ for the parts of the plume that have a convergent eddy heat transport are shown in Fig. 10. They are about $120 \mathrm{mK} / 100 \mathrm{~km}$ at array A and about $160 \mathrm{mK} / 100 \mathrm{~km}$ at array $\mathrm{B}$. While the eddy heat transports are approximately the same at the two upstream arrays, the smaller mean plume velocity at array B leads to the higher eddy induced warming rates. Results from the two interpolation methods differ by $10 \%$ at both arrays.

\section{Conclusions}

A comparison of the overall plume warming rates with the eddy driven plume warming rate shows the relative importance of horizontal and vertical turbulent processes for the entrainment. Figure 10 compares the eddy driven warming rates calculated at the three mooring arrays $\mathrm{A}$ to $\mathrm{C}$ with the warming rates derived from the downstream development of the mean plume temperatures. From array A to array $\mathrm{C}$, the eddy heat transports do explain the warming of the plume and the meso-scale eddies are thus the driving mechanism for the temperature increase in the region farther than $200 \mathrm{~km}$ from the sill. Unfortunately, no eddy driven warming rates between the sill and array A could be calculated in this study. However, it is questionable whether eddies alone lead to a warming rate that is three to four times larger on the first $200 \mathrm{~km}$ behind the sill than in the mooring arrays analysed here. Thus, on the first $200 \mathrm{~km}$ after the sill vertical processes should play an important role in the mixing.

From the results presented here, together with the findings from other studies (Girton, 2001; Girton and Sanford, 2003; Käse et al., 2003), a picture of three different entrainment regimes in the Denmark Strait overflow plume emerges.

The first regime is located between the Denmark Strait sill and $\sim 125 \mathrm{~km}$ downstream of the sill. Here the plume accelerates from a mean speed of about $40 \mathrm{~cm} / \mathrm{s}$ at the sill to its maximum speed of $60 \mathrm{~cm} / \mathrm{s}$. The current has a barotropic structure close to the sill, i.e. there is no strong shear between the overflow plume and the watermasses above. Thus, little vertical turbulence should occur. Rudels et al. (1999) observed a capping of the overflow plume with low salinity water that survived the initial descent of the plume. This suggests that vertical mixing is weak during the initial descent as the capping would be disturbed by the mixing. The overall entrainment is estimated to be one order of magnitude smaller than beyond $125 \mathrm{~km}$ from the sill (Girton and Sanford, 2003). High variability in the bottom current with a dominant time-scale of 1.8 days suggests that eddies are generated in the overflow through baroclinic instability (Smith, 1976).

The region of strong entrainment into the overflow plume characterises the second regime. It reaches approximately to array A $200 \mathrm{~km}$ downstream of the sill as indicated by the 
high plume warming rate. The high plume velocities and the transition to a baroclinic flow lead to large vertical velocity shears. This shear and low Richardson numbers indicate vertical instability.

The third regime beyond $200 \mathrm{~km}$ downstream distance is characterized by the dominance of eddies in the entrainment process. The vertical velocity shear provides the energy to feed baroclinic instabilities. The enhancement of the eddy field already starts at $\sim 125 \mathrm{~km}$, but the eddy mixing becomes the dominant process for the entrainment into the overflow plume here. As the mean plume speed decreases, the velocity shear also decreases and the effect of vertical turbulence diminishes.

Acknowledgements. The financial support for this study by Deutsche Forschungsgemeinschaft (SFB 512 E2), the European Commission (VEINS, ASOF, THOR) and the German Ministry of Education and Research (Nordatlantik Projekt) is gratefully acknowledged. Thanks to Andreas Macrander for providing hydrographic data from the Denmark Strait sill.

Edited by: K. J. Heywood

\section{References}

Bruce, J. G.: Eddies southwest of the Denmark Strait, Deep-Sea Res. Pt. I, 42, 13-29, 1995.

Cenedese, C., Whitehead, J. A., Ascarelli, T. A., and Ohiwa, M.: A Dense Current Flowing down a Sloping Bottom in a Rotating Fluid, J. Phys. Oceanogr., 34, 188-203, 2003.

Dickson, B., Dye, S., Jónsson, S., Köhl, A., Macrander, A., Marnela, M., Meincke, J., Olsen, S., Rudels, B., Valdimarsson, H., and Voet, G.: Arctic-Subarctic Ocean Fluxes, chap. The Overflow Flux West of Iceland: Variability, Origins and Forcing, pp. 443-474, Springer, 2008.

Dickson, R., Rudels, B., Dye, S., Karcher, M., Meincke, J., and Yashayaev, I.: Current estimates of freshwater flux through Arctic and subarctic seas, Prog. Oceanogr., 73, 210-230, 2007.

Dickson, R. R. and Brown, J.: The production of North Atlantic Deep Water: Sources, rates, and pathways, J. Geophys. Res., 99, 12319-12341, 1994.

Geyer, F., Østerhus, S., Hansen, B., and Quadfasel, D.: Observations of highly regular oscillations in the overflow plume downstream of the Faroe Bank Channel, J. Geophys. Res., 111, C12020, doi:10.1029/2006JC003693, 2006.

Girton, J. B.: Dynamics of transport and variability in the Denmark Strait overflow, Ph.D. thesis, University of Washington, Seattle, WA, 2001.

Girton, J. B. and Sanford, T. B.: Descent and Modification of the Overflow Plume in the Denmark Strait, J. Phys. Oceanogr., 33, 1351-1364, 2003.

Hansen, B., Østerhus, S., Quadfasel, D., and Turrell, W.: Already the Day After Tomorrow?, Science, 305, 953-954, 2004.

Høyer, J. L. and Quadfasel, D.: Detection of deep overflows with satellite altimetry, Geophys. Res. Lett., 28, 1611-1614, 2001.
Jiang, L. and Garwood, R. W.: Three-Dimensional Simulations of Overflows on Continental Slopes, J. Phys. Oceanogr., 26, 12141233, 1996.

Jungclaus, J. H., Hauser, J., and Käse, R. H.: Cyclogenesis in the Denmark Strait Overflow Plume, J. Phys. Oceanogr., 31, 32143229, 2001.

Käse, R. H., Girton, J. B., and Sanford, T. B.: Structure and variability of the Denmark Strait Overflow: Model and observations, J. Geophys. Res., 108, C6, 3181, 2003.

Krauss, W.: A note on overflow eddies, Deep-Sea Res. Pt. I, 43, 1661-1667, 1996.

Krauss, W. and Käse, R. H.: Eddy formation in the Denmark Strait overflow, J. Geophys. Res., 103, 15525-15538, 1998.

Macrander, A., Send, U., Valdimarsson, H., Jónsson, S., and Käse, R. H.: Interannual changes in the overflow core from the Nordic Seas into the Atlantic Ocean through Denmark Strait, Geophys. Res. Lett., 32, L06606, doi:10.1029/2004GL021463, 2005.

Mauritzen, C.: Production of dense overflow waters feeding the North Atlantic across the Greenland-Scotland Ridge. Part 1: Evidence for a revised circulation scheme, Deep-Sea Res. Pt. I, 43, 769-806, 1996.

Pawlowicz, R., Beardsley, B., and Lentz, S.: Classical tidal harmonic analysis including error estimates in MATLAB using T_TIDE, Comput. Geosci., 28, 929-937, 2002.

Quadfasel, D. and Käse, R. H.: Ocean Circulation: Mechanisms and Impacts, vol. 173, chap. Present-Day Manifestation of the Nordic Seas Overflows, pp. 75-89, Geophys. Monogr. Ser., AGU, Washington D.C., 2007.

Ross, C. K.: Temperature - salinity characteristics of the "overflow" water in Denmark Strait during "OVERFLOW '73”, Rap. Proces., 185, 111-119, 1984.

Rudels, B., Eriksson, P., Grönvall, H., Hietala, R., and Launiainen, J.: Hydrographic Observations in Denmark Strait in Fall 1997, and their Implications for the Entrainment into the Overflow Plume, Geophys. Res. Lett., 26, 1325-1328, 1999.

Schott, F. A., Zantopp, R., Stramma, L., Dengler, M., Fischer, J., and Wibaux, M.: Circulation and deep-water export at the western exit of the subpolar North Atlantic, J. Phys. Oceanogr., 34, 817-843, 2004.

Smith, P. C.: Baroclinic Instability in the Denmark Strait Overflow, J. Phys. Oceanogr., 6, 355-371, 1976.

Spall, M. A. and Price, J. F.: Mesoscale Variability in Denmark Strait: The PV Outflow Hypothesis, J. Phys. Oceanogr., 28, 1598-1623, 1998.

Stahr, F. R. and Sanford, T. B.: Transport and bottom boundary layer observations of the North Atlantic Deep Western Boundary Current at the Blake Outer Ridge, Deep-Sea Res. Pt. II, 46, 205243, 1999.

Whitehead, J. A., Stern, M. E., Flierl, G. R., and Klinger, B. A.: Experimental Observations of Baroclinic Eddies on a Sloping Bottom, J. Geophys. Res., 95, 9585-9610, 1990.

Worthington, L. V.: An attempt to measure the volume transport of Norwegian Sea overflow water through the Denmark Strait, Deep-Sea Res., 16, supplement, 421-432, 1969. 